\title{
Understanding Barriers to Solar Energy Use in Taiwan Using the Decision Making Trial and Evaluation Laboratory Integrated with the Technique for Order Preference by Similarity to an Ideal Solution
}

\author{
Shu-Mei Lin \\ Graduate Institute of Management of Chang Gung University, Taiwan \\ Email: Victoria9Lin@gmail.com
}

How to cite this paper: Lin, S.-M. (2021) Understanding Barriers to Solar Energy Use in Taiwan Using the Decision Making Trial and Evaluation Laboratory Integrated with the Technique for Order Preference by Similarity to an Ideal Solution. Smart Grid and Renewable Energy, 12, 137-162.

https://doi.org/10.4236/sgre.2021.129009

Received: September 7, 2021

Accepted: September 26, 2021

Published: September 29, 2021

Copyright $\odot 2021$ by author(s) and Scientific Research Publishing Inc. This work is licensed under the Creative Commons Attribution International License (CC BY 4.0).

http://creativecommons.org/licenses/by/4.0/

\begin{abstract}
The aim of this paper was to serve as a reference for the development of renewable energy sources of energy policy in Taiwan by investigating current barriers to solar energy use. Through a meta-analysis of relevant literature, we classified current barriers into 3 dimensions and 13 criteria. Our selected methodology was the Decision Making Trial and Evaluation Laboratory (DEMATEL) integrated with the Technique for Order Preference by Similarity to an Ideal Solution (TOPSIS). This approach enabled us to determine the relationships among the dimensions and criteria. The results indicate the geographical and topographical factors represent the greatest barriers to solar energy development in Taiwan. Our findings serve as a valuable reference for decision-makers both in terms of policy and investment as well as offer a starting point for those working to priority barriers and choose the optimal barrier to the direction sustainable future in solar energy.
\end{abstract}

\section{Keywords}

Energy, Renewable Energy Sources, Energy Policy, DEMATEL and TOPSIS, Solar Energy

\section{Introduction}

\subsection{Contextualization}

In this paper, we analyze relevant literature to construct a conceptual framework of the barriers to the development of solar energy in Taiwan (Figure 1). This 
framework includes 3 dimensions and 13 criteria for the development of solar energy (Table 1). We applied the Decision Making Trial and Evaluation Laboratory (DEMATEL) [1] integrated with the Technique for Order Preference by Similarity to an Ideal Solution (TOPSIS) [2] to determine the cause-effect relationships among these dimensions and criteria. Our findings serve as a reference for decision-makers regarding green energy policy.

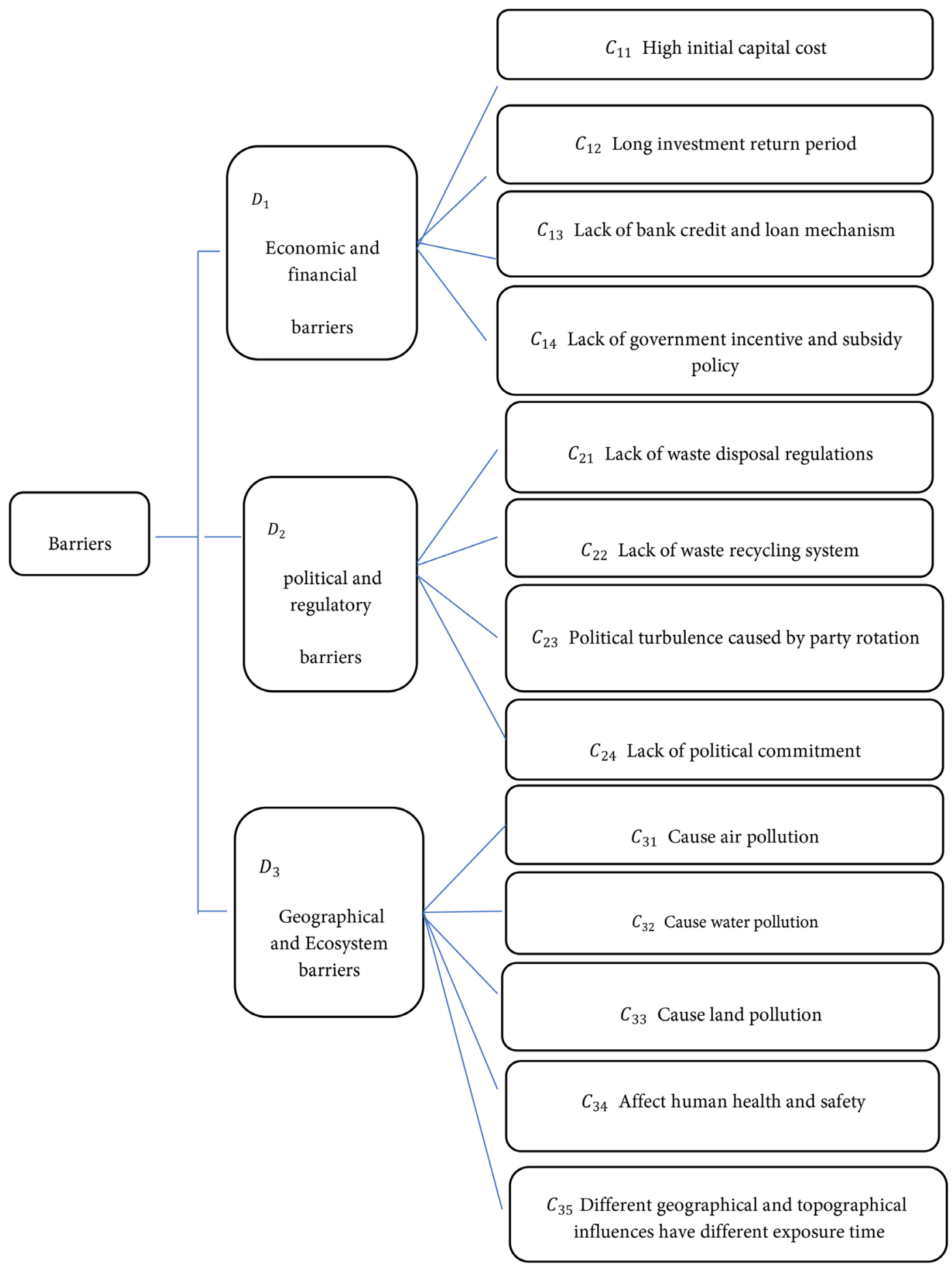

Figure 1. Conceptual framework. 
Table 1. List of barriers to solar energy in Taiwan.

\begin{tabular}{|c|c|c|}
\hline $\begin{array}{l}\text { Dimensions } \\
\text { (Main barriers) }\end{array}$ & Criteria (Sub barriers) & References \\
\hline \multirow{4}{*}{$\begin{array}{l}D_{1} \\
\text { Economic and } \\
\text { financial barriers }\end{array}$} & $C_{11}$ High initial capital cost & {$[4][8][12][14][15][18][20][21][25]$} \\
\hline & $C_{12}$ Long investment return period & [4] [12] [13] [14] [18] \\
\hline & $\begin{array}{l}C_{13} \text { Lack of bank credit and loan } \\
\text { mechanisms }\end{array}$ & $\begin{array}{c}{[4][8][12][15][16][18][19][21]} \\
{[25]}\end{array}$ \\
\hline & $\begin{array}{l}C_{14} \text { Lack of government incentive and } \\
\text { subsidy policy }\end{array}$ & $\begin{array}{c}{[4][8][12][13][14][15][16][18]} \\
{[19][20][21][25]}\end{array}$ \\
\hline \multirow{4}{*}{$\begin{array}{l}D_{2} \\
\text { Political and } \\
\text { regulatory } \\
\text { barriers }\end{array}$} & $C_{21}$ Lack of waste disposal regulations & [11] \\
\hline & $C_{22}$ Lack of waste recycling system & [4] [5] [6] [9] [10] [11] \\
\hline & $\begin{array}{l}C_{23} \text { Political turbulence caused by } \\
\text { party rotation }\end{array}$ & [8] [12] [15] [16] [18] [25] \\
\hline & $C_{24}$ Lack of political commitment & [12] [14] [15] [16] [19] [20] [21] [25] \\
\hline \multirow{5}{*}{$\begin{array}{l}D_{3} \\
\text { Geographical and } \\
\text { ecosystem barriers }\end{array}$} & $C_{31}$ Air pollution & [6] [10] [19] \\
\hline & $C_{32}$ Water pollution & [4] [10] [19] [21] [25] \\
\hline & $C_{33}$ Land pollution & [4] [6] [10] [19] [25] \\
\hline & $C_{34}$ Human health and safety & {$[6][7]$} \\
\hline & $\begin{array}{l}C_{35} \text { Different geographical and } \\
\text { topographical influences result in } \\
\text { different sunlight exposure times }\end{array}$ & [8] [10] [15] [18] [20] [25] \\
\hline
\end{tabular}

\subsection{Relevance of the Literature}

Sorenson [3] defines renewable energy as energy replenishment from natural processes is as fast as consumption. Renewable energy sources such as solar, wind, geothermal, hydropower, and biomass energies feature different energy densities, location requirements, and physical processes [4]. In particular, solar energy is an increasingly popular choice for power generation across the world [4], and it is this renewable source that is favored to fill the electricity gap in Taiwan [3].

There exists a large body of research into solar energy, including its impacts and requirements. [5] recommended that the photovoltaic industry should act to maintain the environmental friendliness of solar energy as a long-term environmental strategy, which could be achieved through the establishment of effective recycling policies. [6] pointed out that the use of conventional energy sources contributes to the sustainable development of human activities. However, their large-scale deployment inevitably exerts adverse environmental impacts, such as greenhouse gas emissions as well as soil and water pollution. [7] acknowledged that the benefits of electricity supply (including that generated from renewable resources) must be weighed against health costs. For example, the cadmium cells used in solar panels represent a well-researched occupational hazard. However, given the estimated 30-year life cycle of photovoltaic units, the risk seems acceptable. [4] investigated the legislation and policy development encouraging 
research and development in the photovoltaic industry. [8] considered the solar energy industry as a whole. [9] declared that the end-of-life management of obsolete photovoltaic modules should avoid landfills, emphasizing that the cost of the recovery process is a key variable of recycling. [10] discussed obstacles to the development of solar energy with an eye to solutions for both research and practice. [11] pointed out that although many solar panel recycling-related activities and processes have been initiated around the world, the majority of solar panels will be abandoned in about 25 years. Therefore, the question arises as to whether the current solution to our energy problem is leading to further environmental heritage waste.

Many researchers have examined the challenges specific to individual countries. [12] considered the dilemma faced by India, which is an emerging economy with a severe shortage of electricity. They proposed that the barriers to solar energy installations are comprised of 6 dimensions and 13 subdimensions [13] considered the same problem but identified 7 dimensions and 28 subdimensions. [14] presented an overview of the challenges faced by Barbados in the deployment of alternative energy. [15] identified and ranked obstacles in Nepal to renewable energy use. [16] pointed out that while Pakistan has a large amount of renewable and sustainable energy resources, it lacks the capacity to use them effectively; indeed, [17] supported this with a ranking of key barriers. [18] further confirmed their findings with their evidence supporting 7 main barriers and 29 sub-barriers. Then, research strategies to overcome these barriers. [19] explored the interrelationships among factors affecting renewable energy in China. [20] assessed Ghana's renewable energy policy goals and built a framework to evaluate each obstacle to these goals. [21] outlined the potential driving force of solar power generation in Vietnam, obstacles to further use of solar energy, and suitable strategies for the next phase of development. In this paper, we draw on this considerable body of research to integrate Taiwan's experience in solar energy.

\subsection{Current Status of Solar Energy Generation in Taiwan}

\subsubsection{Geographical Context}

Taiwan is the fourth highest island in the world with a length of 395 kilometers from north to south and a width of 144 kilometers from east to west. Taiwan can be divided into two climatic regions separated by the tropic of cancer. Taiwan's climate of the north of the tropic of cancer is a subtropical climate and the south is a tropical climate. (Figure 2)

\subsubsection{Present Deployment of Solar Energy in Taiwan}

Despite the fact that Taiwan's natural environment has led to water, electricity, and land shortages, the government nevertheless aims to replace the current nuclear energy supply with renewable energy sources (see Table 2). At present, the share of solar energy generation accounts for less than $0.7 \%$ of total electricity consumption, indicating that there is considerable room for improvement. 


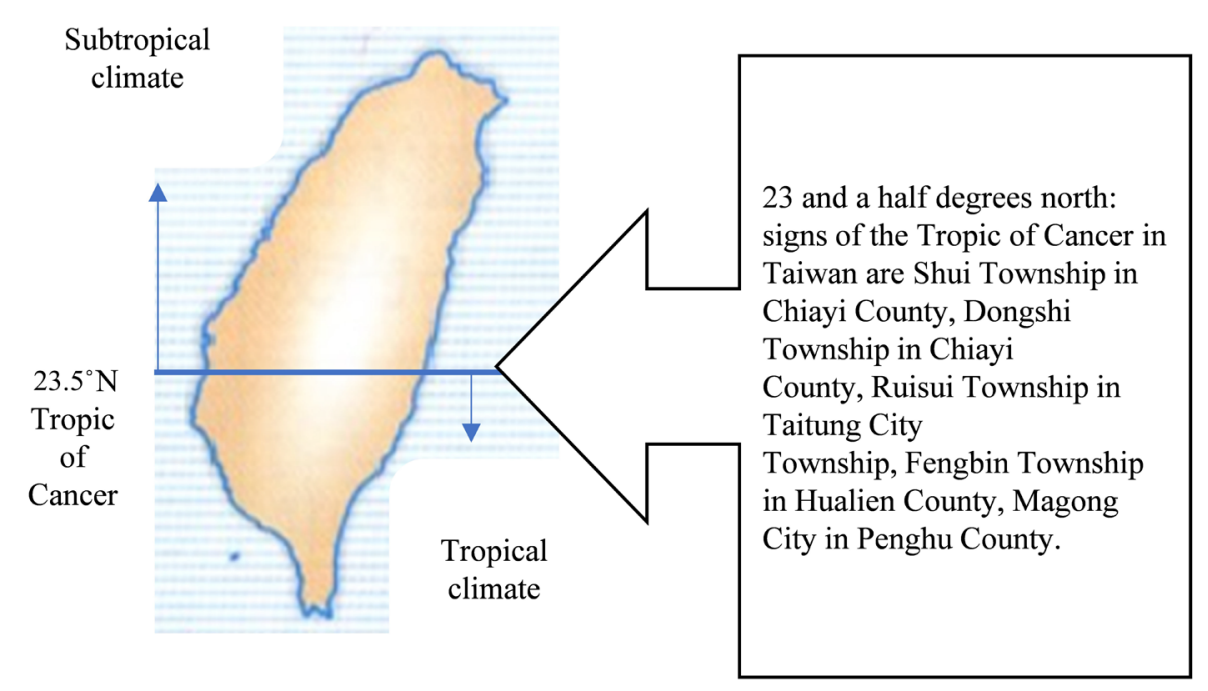

Figure 2. Map of Taiwan showing Tropic of Cancer $\left(23.5^{\circ} \mathrm{N}\right)$ passing through Chiayi County and Hualien County (2021) [22].

Table 2. Energy supply by sectors (\% of total renewable energy) from 2019/03 to 2021/04 (Source: Taiwan Ministry of Economic Affairs (TMOEA) 2021) [23].

\begin{tabular}{|c|c|c|c|c|c|c|c|}
\hline Year & Month & Hydro & Geothermal & Solar PV & Wind & Biomass & Wast \\
\hline \multirow{10}{*}{2019} & 03 & 0.29177 & 0 & 0.26823 & 0.12456 & 0.01633 & 0.29911 \\
\hline & 04 & 0.33861 & 0.00014 & 0.28738 & 0.10420 & 0.01583 & 0.25385 \\
\hline & 05 & 0.52641 & 0.00001 & 0.22207 & 0.05675 & 0.01066 & 0.18410 \\
\hline & 06 & 0.55041 & 0.00004 & 0.21639 & 0.04261 & 0.00869 & 0.19056 \\
\hline & 07 & 0.39733 & 0.00003 & 0.28179 & 0.06692 & 0.01155 & 0.24239 \\
\hline & 08 & 0.63886 & 0.00005 & 0.30899 & 0.06484 & 0.00851 & 0.25684 \\
\hline & 09 & 0.38136 & 0.00007 & 0.28770 & 0.10773 & 0.00595 & 0.21719 \\
\hline & 10 & 0.30073 & 0.00009 & 0.31636 & 0.16952 & 0.00515 & 0.20814 \\
\hline & 11 & 0.21222 & 0.00007 & 0.30560 & 0.24435 & 0.00835 & 0.22941 \\
\hline & 12 & 0.15076 & 0.00012 & 0.29503 & 0.23672 & 0.01603 & 0.30135 \\
\hline \multirow{12}{*}{2020} & 1 & 0.18599 & 0.00004 & 0.29038 & 0.17681 & 0.01462 & 0.33217 \\
\hline & 2 & 0.20283 & 0.00012 & 0.36831 & 0.16067 & 0.01156 & 0.25651 \\
\hline & 3 & 0.18345 & 0.00007 & 0.34552 & 0.24021 & 0.01406 & 0.21668 \\
\hline & 4 & 0.18918 & 0.00038 & 0.42075 & 0.15388 & 0.01414 & 0.22167 \\
\hline & 5 & 0.26084 & 0.00011 & 0.43241 & 0.07034 & 0.01276 & 0.22354 \\
\hline & 6 & 0.26530 & 0.00012 & 0.40280 & 0.11009 & 0.00894 & 0.23274 \\
\hline & 7 & 0.20480 & 0.00012 & 0.47079 & 0.07740 & 0.01028 & 0.23660 \\
\hline & 8 & 0.17711 & 0.00013 & 0.49466 & 0.05697 & 0.00661 & 0.26452 \\
\hline & 9 & 0.18712 & 0.00015 & 0.45660 & 0.09180 & 0.00842 & 0.25590 \\
\hline & 10 & 0.19520 & 0.00012 & 0.38347 & 0.23514 & 0.01043 & 0.17563 \\
\hline & 11 & 0.14721 & 0.00010 & 0.42052 & 0.21776 & 0.05504 & 0.20323 \\
\hline & 12 & 0.16911 & 0.00005 & 0.29068 & 0217522 & 0.03476 & 0.23019 \\
\hline
\end{tabular}




\begin{tabular}{cccccccc}
\multicolumn{1}{c}{ Continued } & \multicolumn{7}{c}{} \\
\hline & 1 & 0.17620 & 0 & 0.32297 & 0.21467 & 0.01549 & 0.27068 \\
2021 & 2 & 0.17033 & 0 & 0.37750 & 0.15682 & 0.01322 & 0.28213 \\
& 3 & 0.13719 & 0.00001 & 0.45945 & 0.15062 & 0.01483 & 0.23790 \\
& 4 & 0.11050 & 0 & 0.52706 & 0.14174 & 0.01288 & 0.20780 \\
\hline
\end{tabular}

Because Taiwan is small, the government intends on using fallow land in each county and releasing at least $1 \%$ of abandoned land to install solar panel systems (Figure 3(1)) to generate more power [8]. The average monthly solar energy potential of each county in Taiwan is presented in Table 3.

\subsubsection{Categories of Solar Energy Development According to Installation Locations}

The rule of thumb suggested by [10] is that a 1-MW solar power plant requires approximately four acres of land (16,187 square meters). Solar systems can be divided into three types: land installations, rooftop installations, and water installations.

1) Land installations

Land installations can be divided into fixed (Figure 3(1)) and sunlight-tracking (Figure 3(2)). For fixed systems, the best sunlight angle is determined by taking into account overall sunlight, inclination, shading, and other environmental factors. Sunlight-tracking systems are $10 \%$ more expensive and are less resilient in the face of strong winds than are fixed ones.

2) Rooftop installations

Within urban areas, tall buildings and other structures can lead to shadowing problems. Therefore, sunlight angle and duration are the most important factors for the installation of rooftop solar systems. In addition, because most buildings have more than one resident or user, it is necessary to obtain a consensus among building residents, which sometimes poses difficulties. Rooftop installations can be supported by scaffolding (Figure 3(3)) or be laid flat on the surface of the roof (Figure 3(4)). Rooftop installations allow for the planting of crops or greenhouse plants that require less sunlight on the land beneath the solar system. They can also form shelter for livestock. This helps reduce the heavy land requirements of solar farms.

3) Water installations

Water reservoirs can be valuable areas for solar system installation, especially in countries with a limited supply of land. Water installations though are subject to unique challenges. In addition to strong winds and rainfall, weather conditions can induce other adverse factors such as high waves, water spray, high-speed water flow, and longshore drift. Long-term humidity increases the probability of corrosion and reduces the lifecycle of a module. Traditional fishing in the area will also be affected. Water installations can be fixed on the surface of the water (Figure 3(5)) or be floating (Figure 3(6)). Taiwan's current water-based solar 
Table 3. Average monthly solar energy potential of counties in Taiwan (cited from [8]).

\begin{tabular}{|c|c|c|c|c|c|c|c|c|}
\hline Month & Taipei & Taichung & Tainan & Kaohsiung & Hualien & Taitung & Taoyuan & Hsinchu \\
\hline Jan & 234 & 434 & 351 & 382 & 234 & 367 & 414 & 473 \\
\hline $\mathrm{Feb}$ & 208 & 322 & 459 & 406 & 262 & 357 & 349 & 459 \\
\hline Mar & 488 & 692 & 586 & 601 & 523 & 641 & 695 & 956 \\
\hline Apr & 527 & 809 & 738 & 1017 & 1307 & 1272 & 664 & 678 \\
\hline May & 346 & 669 & 665 & 672 & 658 & 836 & 515 & 512 \\
\hline Jun & 629 & 972 & 795 & 778 & 1005 & 1217 & 894 & 902 \\
\hline Jul & 782 & 1074 & 933 & 775 & 1280 & 1348 & 974 & 853 \\
\hline Aug & 669 & 1009 & 903 & 658 & 958 & 1076 & 818 & 761 \\
\hline Seg & 412 & 853 & 745 & 719 & 924 & 1043 & 518 & 495 \\
\hline Oct & 621 & 776 & 664 & 605 & 759 & 952 & 829 & 785 \\
\hline Nov & 371 & 581 & 789 & 502 & 705 & 743 & 542 & 560 \\
\hline Dec & 234 & 652 & 611 & 537 & 374 & 732 & 437 & 566 \\
\hline Total & 5522 & 8844 & 8238 & 7650 & 8989 & 10,584 & 7647 & 7998 \\
\hline Month & Chiayi & Pingtung & Yunlin & Nantou & Miaoli & Changhua & Yilan & \\
\hline Jan & 387 & 431 & 398 & 414 & 444 & 424 & 154 & \\
\hline $\mathrm{Feb}$ & 396 & 453 & 349 & 326 & 362 & 324 & 205 & \\
\hline Mar & 689 & 643 & 695 & 797 & 780 & 738 & 365 & \\
\hline Apr & 800 & 1170 & 820 & 1122 & 744 & 928 & 623 & \\
\hline May & 593 & 693 & 555 & 573 & 585 & 627 & 366 & \\
\hline Jun & 678 & 858 & 680 & 793 & 936 & 895 & 548 & \\
\hline Jul & 652 & 832 & 720 & 1032 & 942 & 1057 & 670 & \\
\hline Aug & 613 & 703 & 665 & 792 & 857 & 908 & 561 & \\
\hline Sep & 580 & 753 & 596 & 706 & 633 & 789 & 579 & \\
\hline Oct & 581 & 657 & 596 & 678 & 778 & 730 & 600 & \\
\hline Nov & 622 & 534 & 589 & 592 & 569 & 586 & 412 & \\
\hline Dec & 540 & 573 & 561 & 581 & 610 & 616 & 240 & \\
\hline Total & 7132 & 8299 & 7225 & 8409 & 8238 & 8622 & 5322 & \\
\hline
\end{tabular}

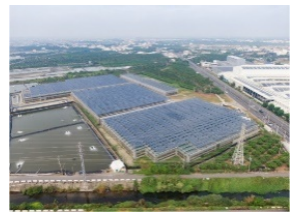

(1)

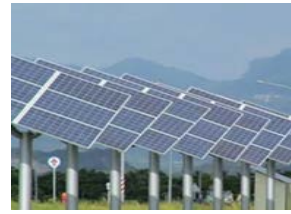

(2)

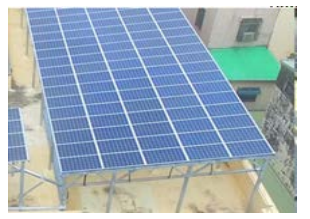

(3)

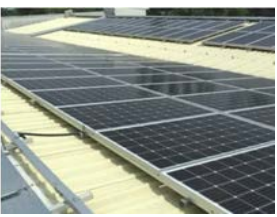

(4)

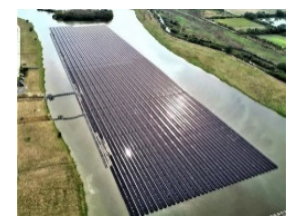

(5)

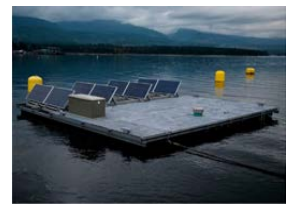

(6)

Figure 3. Solar system types in Taiwan: 1) fixed on land, 2) sunlight-tracking on land, 3) scaffolded on rooftop, 4) flat on rooftop, 5) fixed on water surface, and 6) floating on water (cited from https://blog.sunnyfounder.com/2020/12/24) [24]. 
power stations include Kaohsiung Agongdian Reservoir, Pingtung Dawuding Reservoir, Wulong, Datan Niupu Drainage Detention Basin, and Tainan Yongkang Technology Park Detention Basin. The Ministry of Economic Affairs leads the implementation of solar energy generation projects in reservoirs and flood detention ponds, whereas the Council of Agriculture is responsible for promoting solar power generation projects in Pitang and Yuyuan.

\subsubsection{Overall Barrier Identification}

We collected a large body of references to clarify the obstacles to solar energy development in Taiwan [4]-[21] [25]. Analysis of these revealed three dimensions to these barriers: economic and financial, political and regulatory, and geographical and ecosystem.

\subsection{Assessment of Scope of Barriers to Solar Energy}

Each of the dimensions is comprised of subdimensions which represent the factors influencing solar energy development. There are four economic and financial factors, four political and regulatory factors, and five geographical and ecosystem factors. Details are provided in Table 1. We consider each of these factors in turn.

1) Economic and financial barriers $\left(D_{1}\right)$

Economic and financial aspects are important for every country. We found four specific financial factors were commonly cited in the literature.

- High initial capital cost $\left(C_{11}\right)$

Manufacturing and installing solar systems entail high investment costs. For example, a silicon solar panel system costs around US $\$ 750$ per square meter to install [26]. For developers without sufficient capital, this can represent an insurmountable obstacle. This factor was considered by [4] [10] [12] [14] [15] [16] [18] [20] [21] [25].

- Long return on investment $\left(C_{12}\right)$

Solar systems are expensive to set up, and they only generate a moderate amount of power on a daily basis. Over time, the return on investment is significant. However, it takes about 20 to 30 years [27] for a solar panel system to manifest some level of profit. This point was made by [8] [12] [13] [14] [18].

- Lack of bank credit and loan mechanisms $\left(C_{13}\right)$

Solar energy projects are usually funded by local banks, but they have limited financing capacity. The inability to obtain credit can create difficulties in the financing of new projects [4] [8] [12] [15] [16] [18] [19] [21] [25].

- Lack of government incentive and subsidy policy $\left(C_{14}\right)$

Lack of or limited government incentives and subsidy policies, insufficient regulatory framework, and lack of coherent renewable energy policies create obstacles to solar power generation [4] [8] [12] [13] [14] [15] [16] [18] [19] [20] [21] [25]. In many cases the subsidy policy and related laws and regulations are in place, but there is no substantive implementation of these frameworks. 
2) Political and regulatory barriers $\left(D_{2}\right)$

We identified four factors within the dimension of political and regulatory barriers.

- Lack of waste disposal regulations $\left(C_{21}\right)$

A lack of policies and regulations regarding global solar waste disposal remains an obstacle to solar power generation [11]. Furthermore, once these policies are in place, they need to be adapted to local conditions.

- Lack of waste recycling systems $\left(C_{22}\right)$

There are few waste recycling systems that enable companies to sort, recycle, and reuse solar panel waste. In particular, the safe disposal of batteries and CdTe solar panels is important and requires a reliable waste management system. Proper supervision of the recycling of solar panels is imperative, as pollution is generated during the recycling process, and the energy required for collection, transportation, and recycling must be quantified according to local conditions. The above points were made by [4] [5] [6] [9] [10] [11].

- Political turbulence caused by party rotation $\left(C_{23}\right)$

Unstable politics and government intervention in the domestic market are the main obstacles to renewable energy. This political factor includes corruption, nepotism, and favoritism. In addition, party rotation can lead to incoherence in policies and regulations, resulting in confusion. This factor was considered by [8] [12] [15] [16] [18] [25].

- Lack of political commitment $\left(C_{24}\right)$

There is a shortage of political commitment to solar power generation. This is aggravated by corruption and nepotism. It adversely affects the planning process through lengthy regulatory approval and permit procedures, and through weak and incoherent policy implementation. Renewable energy development would also benefit from the creation of renewable energy zones, and this has yet to be implemented. The above was reported in [12] [14] [15] [16] [19] [20] [21] [25].

3) Geographical and ecosystem barriers $\left(D_{3}\right)$

Geographical and ecosystem barriers are unique to the landscape and climate of each country, but the nature of renewable resources means all are affected to some degree by this dimension. We discuss four important factors.

- Air pollution $\left(C_{31}\right)$

Although the solar energy industry has no direct impact on the environment, solar cells are toxic to the environment. Discharging them is a complex task for manufacturers and consumers, bringing in considerations of environmental protection [6] [10] [19].

- Water pollution $\left(C_{32}\right)$

Environmental impacts related to solar energy include land use and habitat loss, water pollution, and the use of hazardous materials in manufacturing processes [4]. An in-depth study of the potential pollution of a lagoon in Vietnam was conducted by [21]. This factor has also been considered by [4] [10] [19] [25]. 
- Land pollution $\left(C_{33}\right)$

Land use and loss of biological habitat are potential environmental impacts of solar power [4]. In many cases, ecosystems, plants, and fauna are destroyed [18]. Furthermore, substances dissolved by heat from the sun seep into the soil [8]. Solar cells are usually made of various chemicals that are toxic to the environment and discharging them is a challenging social responsibility for manufacturers and consumers [17]. The factor of land pollution was considered by [6] [10] [19] [25].

- Human health $\left(C_{34}\right)$

Cadmium batteries are a known occupational hazard [11]. The dangers associated with the transfer of heated fluids (i.e., water and oil) are also a concern [18]. These health hazards were also discussed by [6] [7].

- Different geographical and topographical influences result in different sunlight exposure times $\left(C_{35}\right)$

The performance of solar panels is greatly affected by the intensity of sunlight [17] and solar energy is often intermittent, with limited daytime hours. The geographical distribution of solar energy resources is also uneven [8]. Pakistan, for example, is an arid tableland surrounded by dry mountains [4]. The effects of this landscape on the scope of solar power generation are further impacted by scattered households [15] [20] [28]. In the work of [8] [10] [18] [25], this factor was discussed in detail.

According to Table 1, we constructed a conceptual framework express as Figure 1.

\section{Methodology}

We conducted DEMATEL integrated with TOPSIS to analyze the barriers represented by the 13 subdimensions described above. We based this analysis on a comprehensive literature review of the selected methodologies to provide a robust theoretical basis for this paper [29]. As described by [30], this approach comprises five steps: 1) construct the research question; 2) look for related articles; 3) select and evaluate articles; 4) analyze and summarize results; and 5) conclude with a narrative-type discussion.

\subsection{Research Framework}

DEMATEL was applied to create a visual model of our conceptual framework and to study the interrelations among its components. This approach was proposed by the Battelle Memorial Institute of the Geneva Research Center between 1972 and 1976 [1]. Its aim is to identify the factors that exert the greatest influence on a selected phenomenon. We conducted DEMATEL and integrated our results using TOPSIS to obtain findings which we present in a traditional narrative-type format. Our research flow is presented in Figure 4.

\subsection{Procedure of DEMATEL}

DEMATEL consists of 10 stages: 1) collecting the results of the questionnaire to 


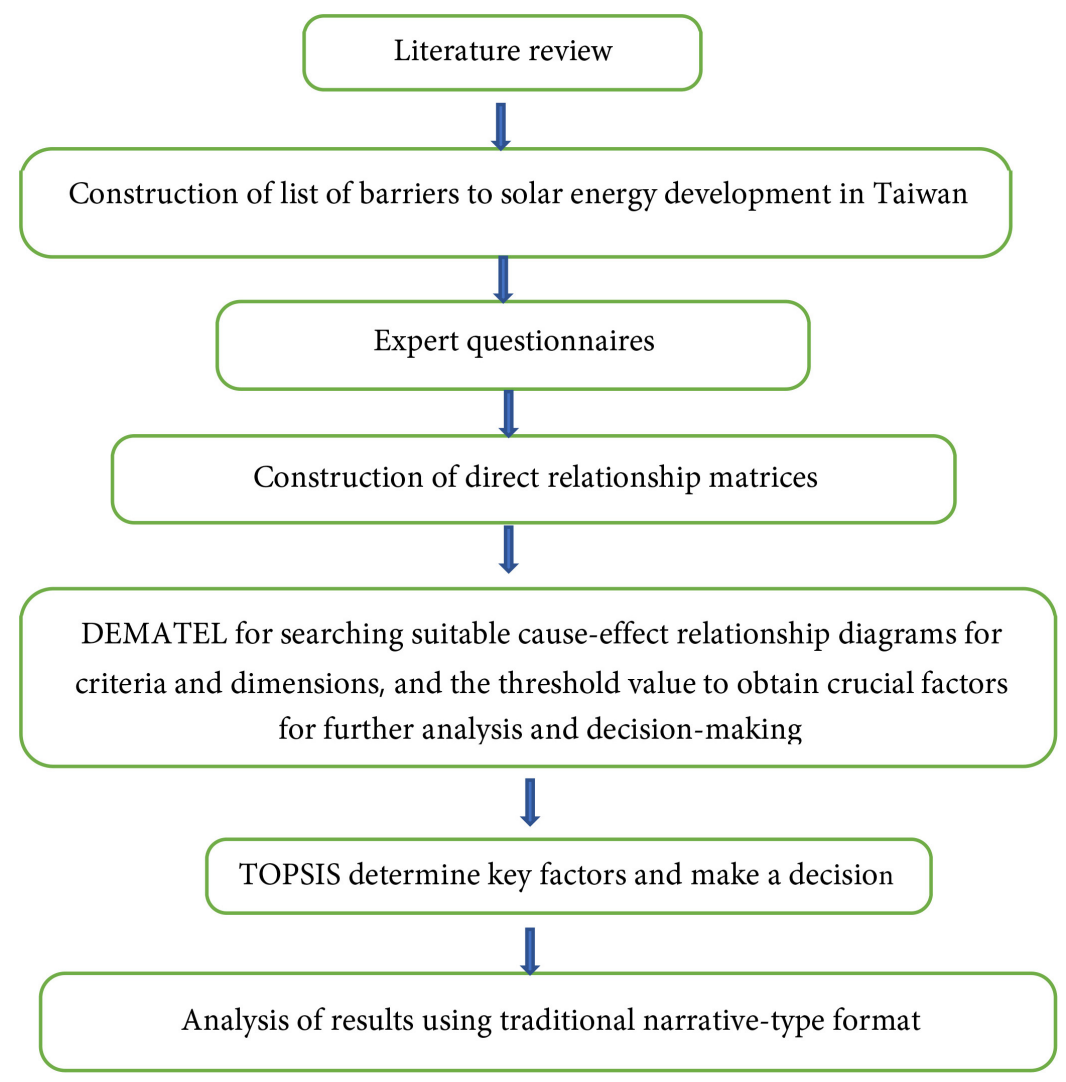

Figure 4. Research flow.

construct matrix $D ; 2$ ) establishing a direct relationship matrix to calculate initial matrix $D$; 3) obtaining normalization matrix $N$; 4) assigning identify matrix $I ; 5)$ expressing extension matrix $I-N ; 6)$ computing inverse matrix $[I-N]^{-1}$;7) calculating total influence relationship matrix $T=N[I-N]^{-1}$;8) calculating $d$, $r, d+r$, and $d-r$ (defined below); 9) drawing a causal diagram; and 10) determining key criteria.

We describe these steps using mathematical notation as follows:

Step 1) Set the number of elements (criteria) $n$. Each criteria is evaluated on a five-point scale as follows: (0) no impact, (1) low impact, (2) medium impact, (3) high impact, and (4) extremely high impact.

Step 2) Establish a direct relationship matrix to compute initial matrix $D$, then $i$ is notation column elements and $j$ is notation row elements, using degree of interaction to obtain matrix $=\left[d_{i j}\right]$, where $d_{i j}$ represents the degree of effect on the $i$ th criteria. When the elements of $i$ have a direct effect on the elements of $j$, then $d_{i j} \neq 0$ and inverse $\left[d_{i j}\right]=0$.

$$
\left[d_{i j}\right]=\left[\begin{array}{ccccc}
d_{11} & \cdots & d_{1 j} & \cdots & d_{1 n} \\
\cdots & & \cdots & & \cdots \\
d_{i 1} & \cdots & d_{i j} & \cdots & d_{i n} \\
\cdots & & \cdots & & \cdots \\
d_{n 1} & \cdots & d_{n j} & \cdots & d_{n n}
\end{array}\right]
$$


Step 3) Obtain normalization matrix $N$ :

$$
N=\left[n_{i j}\right]=\left[\begin{array}{ccccc}
d_{11} / d_{11} & \cdots & d_{1 j} / d_{j j} & \cdots & d_{1 n} / d_{n n} \\
\cdots & & \cdots & & \cdots \\
d_{i 1} / d_{11} & \cdots & d_{i j} / d_{j j} & \cdots & d_{i n} / d_{n n} \\
\cdots & & \cdots & & \cdots \\
d_{n 1} / d_{11} & \cdots & d_{n j} / d_{j j} & \cdots & d_{n n} / d_{n n}
\end{array}\right]
$$

Step 4) Assign identify matrix I:

$$
I=\left[\begin{array}{ccccc}
1 & \cdots & 0 & \cdots & 0 \\
\cdots & 1 & \cdots & 0 & \cdots \\
0 & \cdots & 1 & \cdots & 0 \\
\cdots & 0 & \cdots & 1 & \cdots \\
0 & \cdots & 0 & \cdots & 1
\end{array}\right]
$$

Step 5) Express extension matrix $I-N$ :

$$
I-N=\left[\begin{array}{ccccc}
1-n_{11} & \cdots & -n_{1 j} & \cdots & -n_{1 n} \\
\cdots & & \cdots & & \cdots \\
-n_{i 1} & \cdots & 1-n_{i j} & \cdots & -n_{i n} \\
\cdots & & \cdots & & \cdots \\
-n_{n 1} & \cdots & -n_{n j} & \cdots & 1-n_{n n}
\end{array}\right]
$$

Step 6) Compute inverse matrix $(I-N)^{-1}$ :

$$
(I-N)^{-1}=\left[\begin{array}{ccccc}
\left(1-n_{11}\right)^{-1} & \cdots & \left(-n_{1 j}\right)^{-1} & \cdots & \left(-n_{1 n}\right)^{-1} \\
\cdots & & \cdots & & \cdots \\
\left(-n_{i 1}\right)^{-1} & \cdots & \left(1-n_{i j}\right)^{-1} & \cdots & \left(-n_{i n}\right)^{-1} \\
\cdots & & \cdots & & \cdots \\
\left(-n_{n 1}\right)^{-1} & \cdots & \left(-n_{n j}\right)^{-1} & \cdots & \left(1-n_{n n}\right)^{-1}
\end{array}\right]
$$

Step 7) Compute total relationship matrix $T=N(I-N)^{-1}$ :

$$
\begin{aligned}
& {\left[\left(\frac{d_{11}}{d_{11}}\right)\left(1-n_{11}\right)^{-1} \quad \ldots \quad\left(\frac{d_{1 j}}{d_{j j}}\right)\left(-n_{1 j}\right)^{-1} \quad \ldots \quad\left(\frac{d_{1 n}}{d_{n n}}\right)\left(-n_{1 n}\right)^{-1}\right.}
\end{aligned}
$$

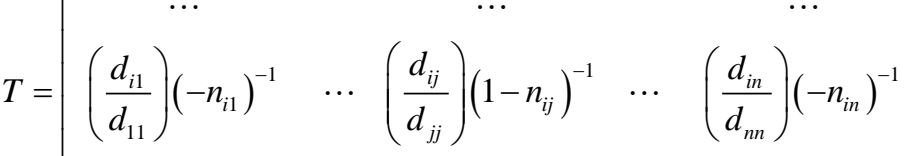

$$
\begin{aligned}
& \left.\left(\frac{d_{n 1}}{d_{11}}\right)\left(-n_{n 1}\right)^{-1} \quad \ldots \quad\left(\frac{d_{n j}}{d_{j j}}\right)\left(-n_{n j}\right)^{-1} \quad \ldots\left(\frac{d_{n n}}{d_{n n}}\right)\left(1-n_{n n}\right)^{-1}\right]
\end{aligned}
$$

Step 8) Calculate $d, r, d+r$, and $d-r$.

Step 9) Draw a causal diagram by mapping the state of $(d+r, d-r)$. Step 10) Determine key criteria. 


\subsection{Procedure of TOPSIS}

TOPSIS was developed in 1981 [2]. It proceeds as follows:

Step 1) Normalize ratings:

$$
r_{i j}=\frac{x_{i j}}{\sqrt{\sum_{i=1}^{m} x_{i j}^{2}}}, i=1, \cdots, m ; j=1, \cdots, n .
$$

Step 2) Weight normalized ratings:

$$
v_{i j}=w_{j} r_{i j}, i=1, \cdots, m ; j=1, \cdots, n,
$$

where $w_{j}$ is the weight of the th attribute.

Step 3) Evaluate the positive and negative solutions (i.e., “*” and “-”):

$$
\begin{aligned}
A^{*} & =\left\{v_{1}^{*}, v_{2}^{*}, \cdots, v_{j}^{*}, \cdots, v_{n}^{*}\right\} \\
& =\left\{\left(\max _{i} v_{i j} \mid j \in J_{1}\right),\left(\min _{i} v_{i j} \mid j \in J_{2}\right) \mid i=1, \cdots, m\right\} \\
A^{-} & =\left\{v_{1}^{-}, v_{2}^{-}, \cdots, v_{j}^{-}, \cdots, v_{n}^{-}\right\} \\
& =\left\{\left(\min _{i} v_{i j} \mid j \in J_{1}\right),\left(\max _{i} v_{i j} \mid j \in J_{2}\right) \mid i=1, \cdots, m\right\}
\end{aligned}
$$

where $J_{1}$ denotes benefit attributes and $J_{2}$ denotes cost attributes.

Step 4) Obtain separation measures:

The positive solutions are ranked according to

$$
S_{i}^{*}=\sqrt{\sum_{j=1}^{n}\left(v_{i j}-v_{j}^{*}\right)^{2}}, i=1, \cdots, m .
$$

Similarly, the negative solutions are ranked according to

$$
S_{i}^{-}=\sqrt{\sum_{j=1}^{n}\left(v_{i j}-v_{j}^{-}\right)^{2}}, i=1, \cdots, m .
$$

Step 5) Find similarities to positive ideal solution:

$$
C_{i}^{*}=\frac{S_{i}^{-}}{S_{i}^{*}+S_{i}^{-}}, \quad i=1, \cdots, m .
$$

Note that $0 \leq C_{i}^{*} \leq 1$, where $C_{i}^{*}=0$ when $A_{i}=A^{-}$and $C_{i}^{*}=0$ when $A_{i}=A^{*}$.

Step 6) Rank preference order:

Select the alternatives with the $\max C_{i}^{*}$, or rank the criteria based on $C_{i}^{*}$ in descending order.

\section{Numerical Experiments}

We invited three experts, each with more than three years of experience in the field, to participate in our study. We created a questionnaire with a 5-point Likert-type scale to collect the opinions of the invited experts on the importance of the different barriers hindering the development of solar energy in Taiwan.

We analyzed a large body of literature to select 13 criteria affecting solar energy development. These factors represent the criteria of 3 dimensions. We then applied DEMATEL and TOPSIS to finding out the cause-effect relationship and rank these dimensions and criteria. In order to obtain an appropriate impact- 
digraph, setting a threshold value of the influence level is necessary for the decision maker. Only some elements, whose influence level in matrix $D$ higher than the threshold value, can be chosen and converted into the impact-digraph. The threshold value is decided by the decision makers. Like matrix $D$, contextual relation among the elements of matrix $D$ can also be converted into a digraph. If the threshold value is too low, the diagraph will be too complex to show the necessary information for decision-making. If the threshold value is too high, many factors will be presented as independent factors without relations to another factor. Then step by step, we get $d, r, d+r$, and $d-r$, defined $d$ represents the sum of all rows of the total effect matrix $T$, meaning directly or indirectly affects degree; $r$ represents the sum of all columns of the total effect matrix $T$, meaning affected by other criteria. $D+r$, presents the degree of relationship between the factors, meaning "prominence". $d-r$, presents the degree of effect and effected for the factors, meaning "relation". If $(d-r)$ is positive, then factor is affecting other factors; if $(d-r)$ is negative, then factor is being affected by other factors. In the following, we present the results of this process.

\subsection{Application of DEMATEL and TOPSIS}

\subsubsection{Draw the Cause-Effect Relationship Diagrams for Criteria}

Based on the empirical study survey, the cause-effect relationship matrices for the criteria evaluated by expert A are presented in Tables 4-6. The cause-effect relationship diagram belonging to expert A for the criteria is depicted in Figure 5. In the following tables, values above the thresholds are marked in bold.

As shown in Figure 5, some of the dimensions and criteria have positive ( $d-$ $r)$ values, such as $D_{1}$ and $C_{12}$. This means that this barrier within this dimension exerts greater influence than the others. We can see that $C_{12}$ is the most important

Table 4. The cause-effect relationship matrix for criteria in $D_{1}$ (expert A).

\begin{tabular}{ccccccccccc}
\hline & $C_{11}$ & $C_{12}$ & $C_{13}$ & $C_{14}$ & $d$ & $r$ & $d+r$ & Rank & $d-r$ & Rank \\
\hline$C_{11}$ & $\mathbf{0 . 8 8 5}$ & $\mathbf{0 . 8 7 7}$ & $\mathbf{0 . 8 5 4}$ & $\mathbf{0 . 8 5 5}$ & 3.471 & 3.283 & 6.754 & 1 & 0.188 & 2 \\
$C_{12}$ & $\mathbf{0 . 8 8 2}$ & $\mathbf{0 . 7 6 1}$ & $\mathbf{0 . 8 1 7}$ & $\mathbf{0 . 7 8 2}$ & 3.242 & 3.049 & 6.291 & 2 & $\mathbf{0 . 1 9 3}$ & $\mathbf{1}$ \\
$C_{13}$ & $\mathbf{0 . 7 5 3}$ & 0.700 & 0.656 & 0.701 & 2.81 & 3.035 & 5.854 & 3 & -0.225 & 4 \\
$C_{14}$ & $\mathbf{0 . 7 6 3}$ & $\mathbf{0 . 7 1 1}$ & 0.708 & 0.636 & 2.818 & 2.974 & 5.792 & 4 & -0.156 & 3 \\
\hline
\end{tabular}

Threshold value: 0.771 .

Table 5. The cause-effect relationship matrix for criteria in $D_{2}$ (expert A).

\begin{tabular}{ccccccccccc}
\hline & $C_{21}$ & $C_{22}$ & $C_{23}$ & $C_{24}$ & $d$ & $r$ & $d+r$ & Rank & $d-r$ & Rank \\
\hline$C_{21}$ & 0.734 & $\mathbf{0 . 8 4 6}$ & $\mathbf{0 . 8 6 3}$ & 0.784 & 3.227 & 3.051 & 6.278 & 3 & $\mathbf{0 . 1 7 6}$ & $\mathbf{1}$ \\
$C_{22}$ & $\mathbf{0 . 8 1 9}$ & $\mathbf{0 . 8 1 6}$ & $\mathbf{0 . 8 9 2}$ & $\mathbf{0 . 8 1 1}$ & 3.338 & 3.266 & 6.604 & 1 & 0.072 & 2 \\
$C_{23}$ & 0.758 & $\mathbf{0 . 8 1 1}$ & 0.788 & $\mathbf{0 . 7 8 7}$ & 3.133 & 3.371 & 6.504 & 2 & -0.238 & 3 \\
$C_{24}$ & 0.740 & 0.793 & $\mathbf{0 . 8 2 8}$ & 0.711 & 3.072 & 3.093 & 6.165 & 4 & -0.021 & 4 \\
\hline
\end{tabular}

Threshold value: 0.798 . 

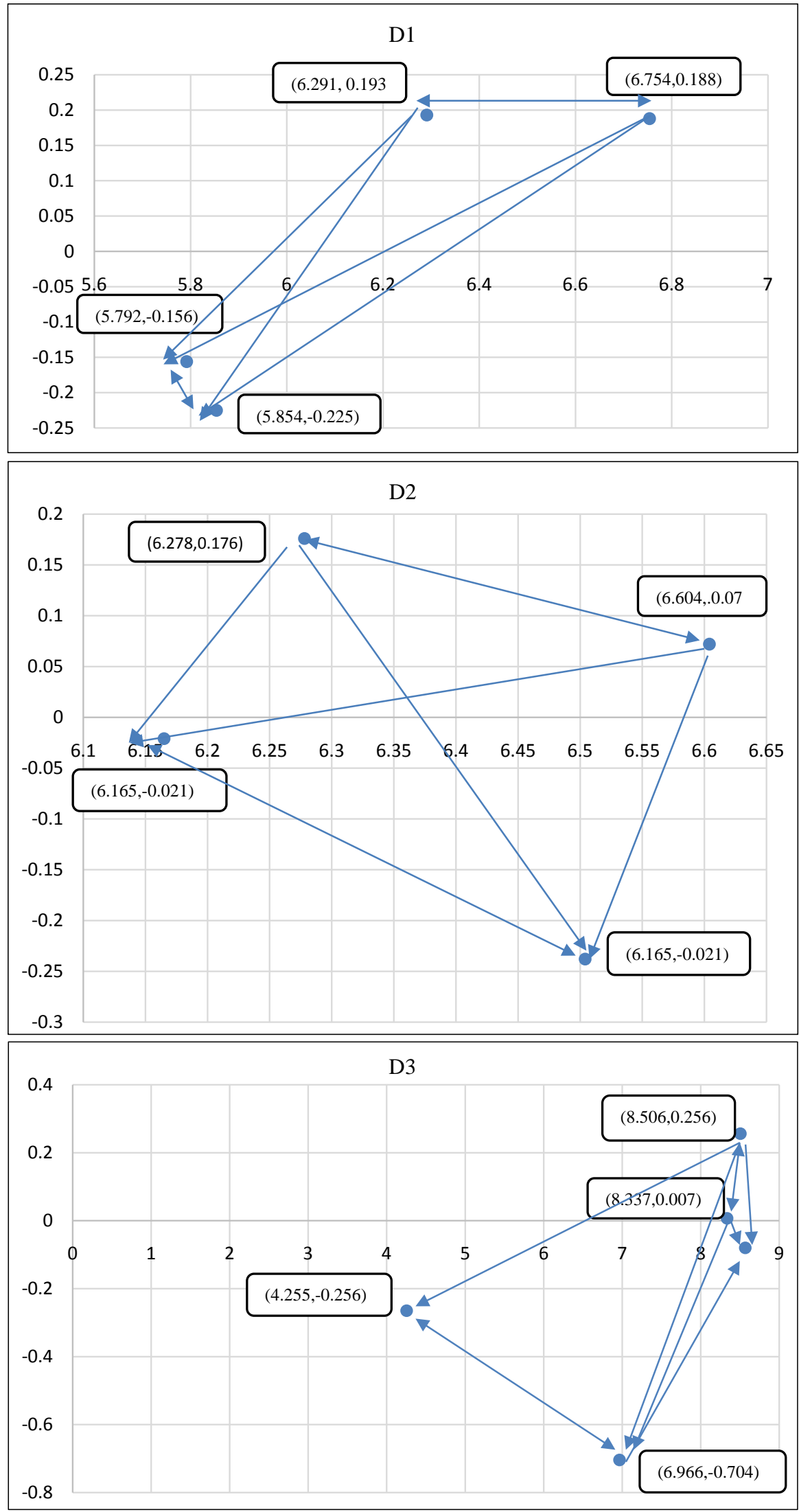

Figure 5. The cause-effect relationship diagram of expert A. 
Table 6. The cause-effect relationship matrix for criteria in $D_{3}$ (expert A).

\begin{tabular}{cccccccccccc}
\hline & $C_{31}$ & $C_{32}$ & $C_{33}$ & $C_{34}$ & $C_{35}$ & $d$ & $r$ & $d+r$ & Rank & $d-r$ & Rank \\
\hline$C_{31}$ & 0.688 & $\mathbf{0 . 8 3 9}$ & 0.793 & $\mathbf{0 . 8 1 1}$ & $\mathbf{0 . 7 8 6}$ & 3.131 & 3.835 & 6.966 & 4 & -0.704 & 5 \\
$C_{32}$ & $\mathbf{0 . 7 9 6}$ & $\mathbf{0 . 8 3 7}$ & $\mathbf{0 . 8 6 7}$ & $\mathbf{0 . 8 8 5}$ & $\mathbf{0 . 8 5 9}$ & 4.244 & 4.324 & 8.568 & 1 & -0.08 & 3 \\
$C_{33}$ & $\mathbf{0 . 7 9 6}$ & $\mathbf{0 . 8 7 7}$ & 0.791 & $\mathbf{0 . 8 6 7}$ & $\mathbf{0 . 8 4 1}$ & 4.172 & 4.165 & 8.337 & 3 & 0.007 & 2 \\
$C_{34}$ & 0.734 & $\mathbf{0 . 8 4 6}$ & $\mathbf{0 . 8 2 0}$ & 0.778 & $\mathbf{0 . 8 1 2}$ & 3.99 & 4.255 & 4.255 & 5 & -0.256 & 4 \\
$C_{35}$ & $\mathbf{0 . 8 2 1}$ & 0.925 & $\mathbf{0 . 8 9 4}$ & $\mathbf{0 . 9 1 4}$ & $\mathbf{0 . 8 2 7}$ & 4.381 & 4.125 & 8.506 & 2 & $\mathbf{0 . 2 5 6}$ & $\mathbf{1}$ \\
\hline
\end{tabular}

Threshold value: 0.796 .

criteria in $D_{1}$. This confirms the findings of [4] [10] [12] [14] [18]. We can also see that some criteria have positive $(d-r)$ values and $C_{21}$ is the most important criteria in $D_{2}$, supporting the results of [11]. Furthermore, $C_{35}$ is the most important criteria in $D_{3}$, as found by [8] [13] [15] [17] [20] [25]. The cause-effect relationship matrices for the criteria evaluated by expert $B$ are presented in Tables 7-9. The cause-effect relationship diagram belonging to expert B for the criteria is depicted in Figure 6. In the following tables, values above the thresholds are marked in bold.

In Figure 6, positive values for $(d-r)$ indicate greater influence. We can see that expert $\mathrm{B}$ believes that $C_{11}$ is the greatest barrier in dimension of economic and financial barriers (i.e., $D_{1}$ ). This was also found by [7] [8] [10] [12] [13] [15] [21]. $C_{22}$ is considered the most important barrier for the sub-barrier in $D_{2}$, confirming the results of [5] [8] [9] [10] [18] [25]. The work of [8] [13] [15] [17] [20] [25] was supported by our finding in which $C_{35}$ is the most important criteria in $D_{3}$. The cause-effect relationship matrices for the criteria evaluated by expert $\mathrm{C}$ are presented in Tables 10-12. The cause-effect relationship diagram belonging to expert $\mathrm{C}$ for the criteria is depicted in Figure 7. In the following tables, values above the thresholds are marked in bold.

In Figure 7, we see positive values of $(d-r)$ for $C_{11}$ in $D_{1}$.

This supports the findings of [3] [8] [10] [12] [14] [15] [16] [18] [20] [21] similarly, positive values for $C_{21}$ in $D_{2}$ support the findings of [11], and positive values for $C_{33}$ in $D_{3}$ support the findings of [3] [6] [10] [19] [25].

\subsubsection{Impact of the Cause-Effect Relationship Diagram for Dimensions} The cause-effect relationship matrices for the dimensions are shown in Tables 13-15, and the impact of the cause-effect relationship diagram for experts A, B, and $\mathrm{C}$ is presented in Figure 8. In the following tables, values above the thresholds are marked in bold.

As shown in Figure 8, expert A weights the third dimension of geography and ecosystem as the dimension that represents the greatest barriers. This is supported by expert $\mathrm{B}$.

\subsection{Application of TOPSIS}

Based on the results of DEMATEL, we set the weights for TOPSIS as follows: 0.2, 0.3 , and 0.5 . We then applied the steps described above. 

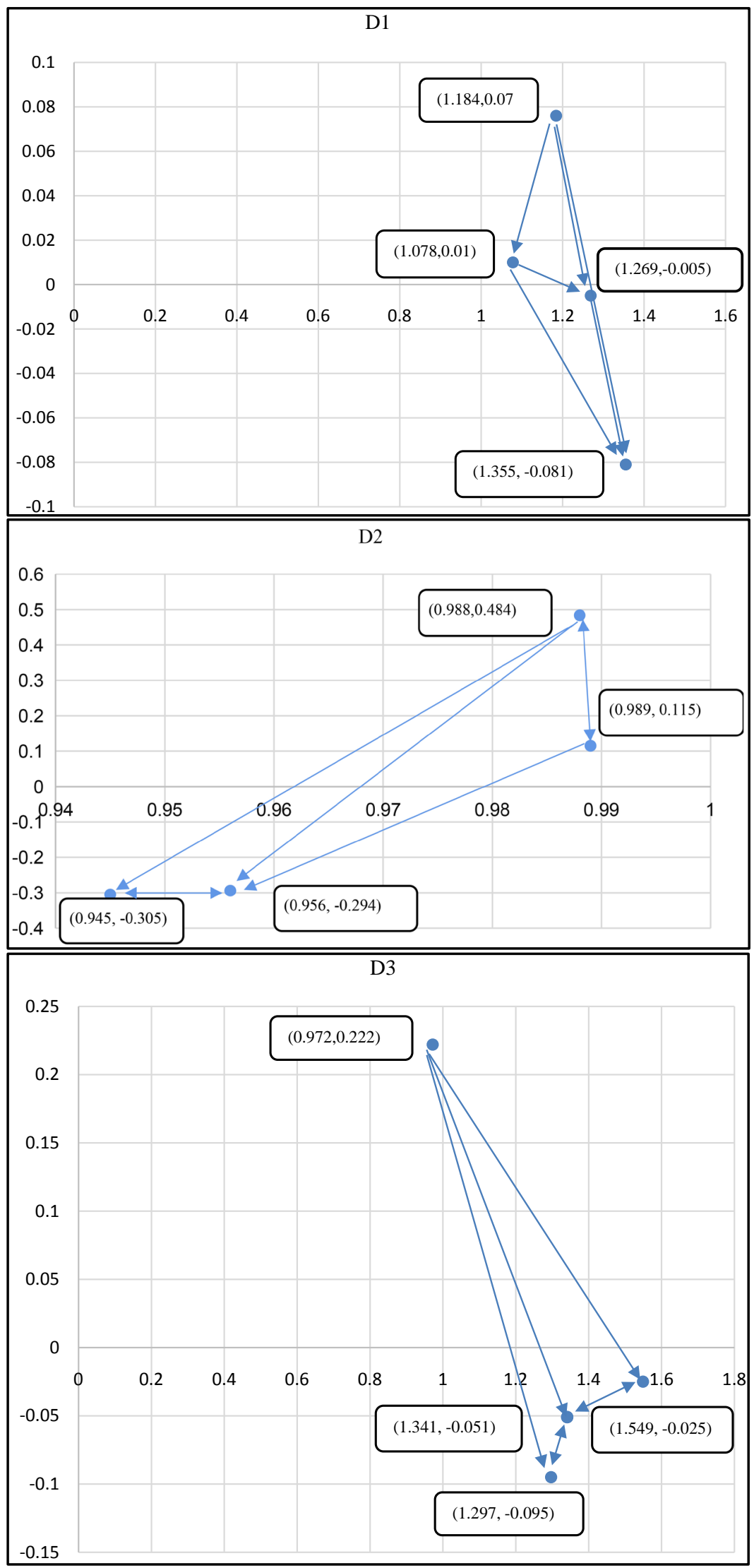

Figure 6. The cause-effect relationship diagram of expert B. 

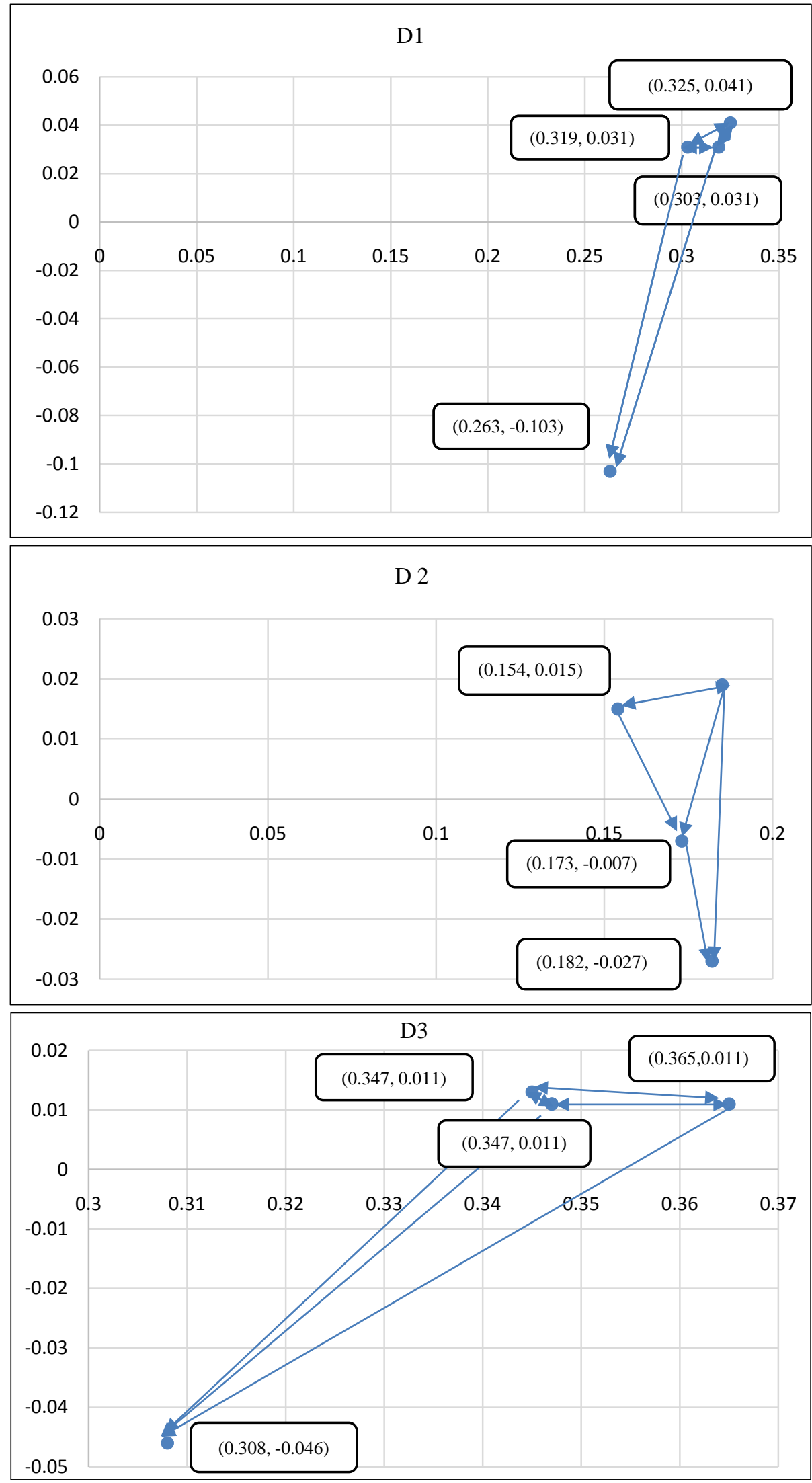

Figure 7. The cause-effect relationship diagram of expert C. 

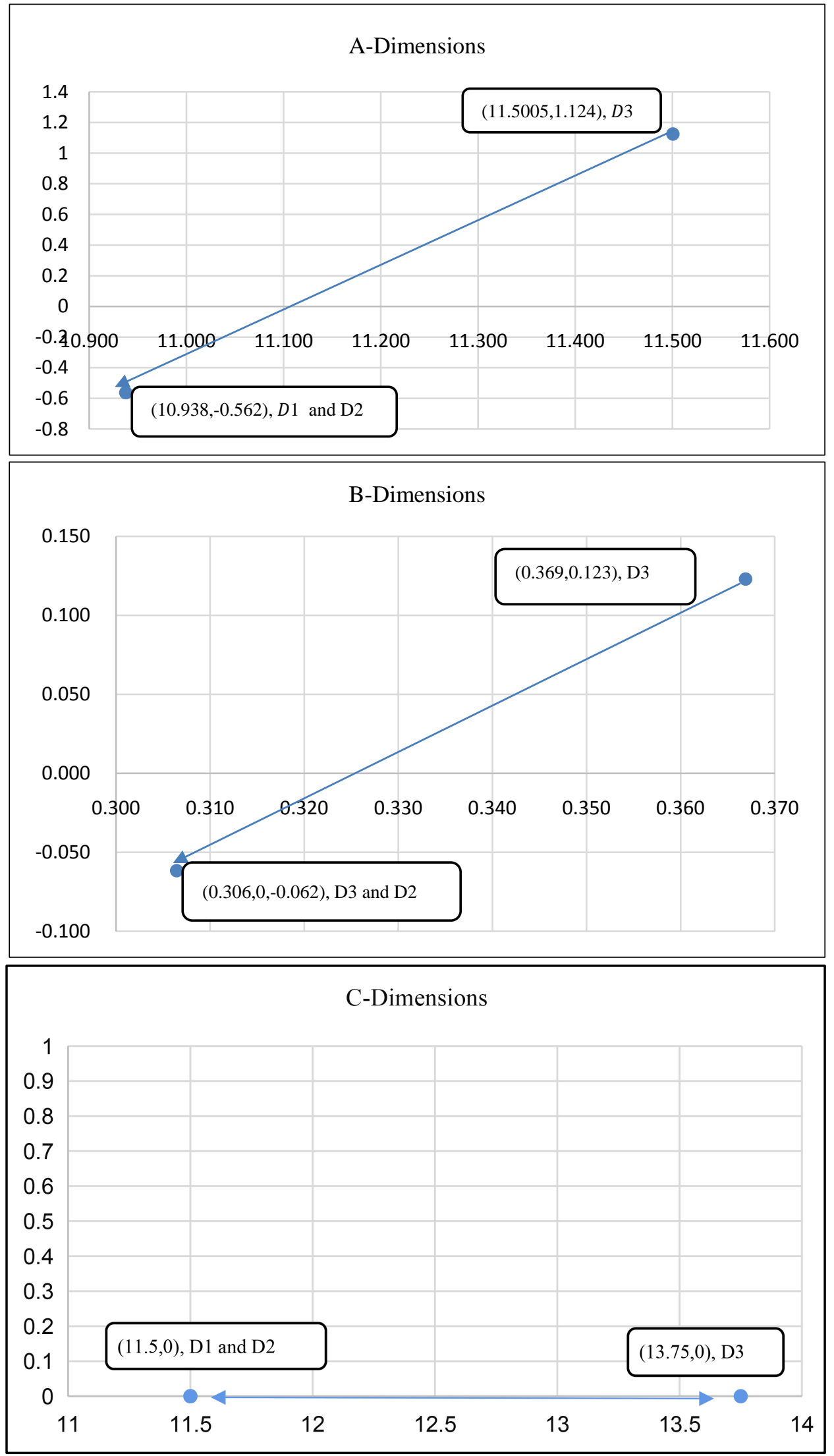

Figure 8. Impact cause-effect diagram of experts A, B, and C. 
Table 7. The cause-effect relationship matrix for criteria in $D_{1}$ (expert B).

\begin{tabular}{ccccccccccc}
\hline & $C_{11}$ & $C_{12}$ & $C_{13}$ & $C_{14}$ & $d$ & $r$ & $d+r$ & Rank & $d-r$ & Rank \\
\cline { 1 - 8 }$C_{11}$ & 0.112 & $\mathbf{0 . 1 7 5}$ & $\mathbf{0 . 1 6 1}$ & $\mathbf{0 . 1 8 2}$ & 0.63 & 0.554 & 1.184 & 3 & $\mathbf{0 . 0 7 6}$ & \multirow{1}{1}{ 1 } \\
$C_{12}$ & $\mathbf{0 . 1 6 6}$ & 0.121 & $\mathbf{0 . 1 6 3}$ & $\mathbf{0 . 1 8 2}$ & 0.632 & 0.637 & 1.269 & 2 & -0.005 & 3 \\
$C_{13}$ & 0.106 & $\mathbf{0 . 1 6 6}$ & 0.100 & $\mathbf{0 . 1 7 2}$ & 0.544 & 0.534 & 1.078 & 4 & 0.01 & 2 \\
$C_{14}$ & $\mathbf{0 . 1 7 0}$ & $\mathbf{0 . 1 7 5}$ & 0.110 & $\mathbf{0 . 1 8 2}$ & 0.637 & 0.718 & 1.355 & 1 & -0.081 & 4 \\
\hline
\end{tabular}

Threshold value: 0.152 .

Table 8. The cause-effect relationship matrix for criteria in $D_{2}$ (expert B).

\begin{tabular}{ccccccccccc}
\hline & $C_{21}$ & $C_{22}$ & $C_{23}$ & $C_{24}$ & $d$ & $r$ & $d+r$ & Rank & $d-r$ & Rank \\
\hline$C_{21}$ & 0.095 & 0.111 & $\mathbf{0 . 1 7 3}$ & $\mathbf{0 . 1 7 3}$ & 0.552 & 0.437 & 0.989 & 1 & 0.115 & 2 \\
$C_{22}$ & $\mathbf{0 . 1 7 8}$ & 0.110 & $\mathbf{0 . 2 2 4}$ & $\mathbf{0 . 2 2 4}$ & 0.736 & 0.252 & 0.988 & 2 & $\mathbf{0 . 4 8 4}$ & $\mathbf{1}$ \\
$C_{23}$ & 0.083 & 0.016 & 0.089 & $\mathbf{0 . 1 4 3}$ & 0.331 & 0.625 & 0.956 & 3 & -0.294 & 3 \\
$C_{24}$ & 0.081 & 0.015 & $\mathbf{0 . 1 3 9}$ & 0.085 & 0.32 & 0.625 & 0.945 & 4 & -0.305 & 4 \\
\hline
\end{tabular}

Threshold value: 0.121 .

Table 9. The cause-effect relationship matrix for criteria in $D_{3}$ (expert B).

\begin{tabular}{cccccccccccc}
\hline & $C_{31}$ & $C_{32}$ & $C_{33}$ & $C_{34}$ & $C_{35}$ & $d$ & $r$ & $d+r$ & Rank & $d-r$ & Rank \\
\hline$C_{31}$ & 0.113 & $\mathbf{0 . 1 4 1}$ & $\mathbf{0 . 1 4 1}$ & 0.175 & 0.075 & 0.645 & 0.696 & 1.341 & 2 & -0.051 & 3 \\
$C_{32}$ & $\mathbf{0 . 1 3 1}$ & 0.103 & $\mathbf{0 . 1 3 1}$ & 0.164 & 0.072 & 0.601 & 0.696 & 1.297 & 4 & -0.095 & 5 \\
$C_{33}$ & $\mathbf{0 . 1 4 1}$ & $\mathbf{0 . 1 4 1}$ & 0.113 & 0.175 & 0.075 & 0.645 & 0.696 & 1.341 & 2 & -0.051 & 3 \\
$C_{34}$ & $\mathbf{0 . 1 8 1}$ & $\mathbf{0 . 1 8 1}$ & $\mathbf{0 . 1 8 1}$ & 0.136 & 0.083 & 0.762 & 0.787 & 1.549 & 1 & -0.025 & 2 \\
$C_{35}$ & $\mathbf{0 . 1 3 0}$ & $\mathbf{0 . 1 3 0}$ & $\mathbf{0 . 1 3 0}$ & 0.137 & 0.070 & 0.597 & 0.375 & 0.972 & 5 & $\mathbf{0 . 2 2 2}$ & $\mathbf{1}$ \\
\hline
\end{tabular}

Threshold value: 0.13 .

Table 10. The cause-effect relationship matrix for criteria in $D_{1}$ (expert C).

\begin{tabular}{ccccccccccc}
\hline & $C_{11}$ & $C_{12}$ & $C_{13}$ & $C_{14}$ & $d$ & $r$ & $d+r$ & Rank & $d-r$ & Rank \\
\hline$C_{11}$ & 0.024 & $\mathbf{0 . 0 4 2}$ & 0.039 & $\mathbf{0 . 0 7 8}$ & 0.183 & 0.142 & 0.325 & 1 & $\mathbf{0 . 0 4 1}$ & $\mathbf{1}$ \\
$C_{12}$ & 0.040 & 0.023 & 0.039 & $\mathbf{0 . 0 7 3}$ & 0.175 & 0.144 & 0.319 & 2 & 0.031 & 2 \\
$C_{13}$ & 0.040 & 0.040 & 0.021 & $\mathbf{0 . 0 6 6}$ & 0.167 & 0.136 & 0.303 & 3 & 0.031 & 2 \\
$C_{14}$ & 0.038 & 0.039 & 0.037 & $\mathbf{0 . 0 4 6}$ & 0.16 & 0.263 & 0.263 & 4 & -0.103 & 4 \\
\hline
\end{tabular}

Threshold value: 0.042

Table 11. The cause-effect relationship matrix for criteria in $D_{2}$ (expert C).

\begin{tabular}{ccccccccccc}
\hline & $C_{21}$ & $C_{22}$ & $C_{23}$ & $C_{24}$ & $d$ & $r$ & $d+r$ & Rank & $d-r$ & Rank \\
\hline$C_{21}$ & $\mathbf{0 . 0 4 8}$ & $\mathbf{0 . 0 4 9}$ & $\mathbf{0 . 0 4 9}$ & $\mathbf{0 . 0 5 8}$ & 0.204 & 0.185 & 0.185 & 1 & $\mathbf{0 . 0 1 9}$ & $\mathbf{1}$ \\
$C_{22}$ & $\mathbf{0 . 0 4 3}$ & 0.024 & $\mathbf{0 . 0 5 1}$ & $\mathbf{0 . 0 5 1}$ & 0.169 & 0.154 & 0.154 & 4 & 0.015 & 2 \\
$C_{23}$ & $\mathbf{0 . 0 4 3}$ & $\mathbf{0 . 0 4 9}$ & 0.024 & $\mathbf{0 . 0 5 0}$ & 0.166 & 0.173 & 0.173 & 3 & -0.007 & 3 \\
$C_{24}$ & $\mathbf{0 . 0 5 1}$ & 0.032 & $\mathbf{0 . 0 4 9}$ & 0.023 & 0.155 & 0.182 & 0.182 & 2 & -0.027 & 4 \\
\hline
\end{tabular}

Threshold value: 0.043 . 
Table 12. The cause-effect relationship matrix for criteria in $D_{3}$ (expert C).

\begin{tabular}{cccccccccccc}
\hline & $C_{31}$ & $C_{32}$ & $C_{33}$ & $C_{34}$ & $C_{35}$ & $d$ & $r$ & $d+r$ & Rank & $d-r$ & Rank \\
\hline$C_{31}$ & 0.025 & $\mathbf{0 . 0 4 1}$ & $\mathbf{0 . 0 4 0}$ & $\mathbf{0 . 0 4 1}$ & $\mathbf{0 . 0 4 1}$ & 0.188 & 0.177 & 0.365 & 4 & 0.011 & 2 \\
$C_{32}$ & $\mathbf{0 . 0 4 1}$ & 0.021 & $\mathbf{0 . 0 3 9}$ & $\mathbf{0 . 0 3 9}$ & $\mathbf{0 . 0 3 9}$ & 0.179 & 0.168 & 0.347 & 1 & 0.011 & 2 \\
$C_{33}$ & $\mathbf{0 . 0 4 1}$ & $\mathbf{0 . 0 3 9}$ & 0.021 & $\mathbf{0 . 0 3 9}$ & $\mathbf{0 . 0 3 9}$ & 0.179 & 0.166 & 0.345 & 3 & $\mathbf{0 . 0 1 3}$ & $\mathbf{1}$ \\
$C_{34}$ & $\mathbf{0 . 0 4 1}$ & $\mathbf{0 . 0 3 9}$ & $\mathbf{0 . 0 3 9}$ & 0.021 & $\mathbf{0 . 0 3 9}$ & 0.179 & 0.168 & 0.347 & 1 & 0.011 & 2 \\
$C_{35}$ & 0.029 & 0.028 & 0.027 & 0.028 & 0.019 & 0.131 & 0.177 & 0.308 & 5 & -0.046 & 5 \\
\hline
\end{tabular}

Threshold value: 0.034 .

Table 13. The cause-effect relationship matrix for dimensions in expert A.

\begin{tabular}{cccccccccc}
\hline & $D_{1}$ & $D_{2}$ & $D_{3}$ & $d$ & $r$ & $d+r$ & Rank & $d-r$ & Rank \\
\hline$D_{1}$ & 1.659 & 1.841 & 1.688 & 5.188 & 5.750 & 10.938 & 2 & -0.562 & 2 \\
$D_{2}$ & 1.841 & 1.659 & 1.688 & 5.188 & 5.750 & 10.938 & 2 & -0.562 & 2 \\
$D_{3}$ & 2.25 & 2.25 & 1.813 & 6.3125 & 5.188 & 11.5005 & 1 & 1.1245 & 1 \\
\hline
\end{tabular}

Threshold value: 1.854 .

Table 14. The cause-effect relationship matrix for dimensions in expert B.

\begin{tabular}{cccccccccc}
\hline & $D_{1}$ & $D_{2}$ & $D_{3}$ & $d$ & $r$ & $d+r$ & Rank & $d-r$ & Rank \\
\hline$D_{1}$ & -0.082 & $\mathbf{0 . 0 8 2}$ & $\mathbf{0 . 1 2 2}$ & 0.122 & 0.184 & 0.306 & 2 & -0.062 & 2 \\
$D_{2}$ & $\mathbf{0 . 0 8 2}$ & -0.082 & $\mathbf{0 . 1 2 2}$ & 0.122 & 0.184 & 0.306 & 2 & -0.062 & 2 \\
$D_{3}$ & $\mathbf{0 . 1 8 4}$ & $\mathbf{0 . 1 8 4}$ & -0.122 & 0.245 & 0.122 & 0.367 & 1 & 0.123 & 1 \\
\hline
\end{tabular}

Threshold value: 0.054 .

Table 15. The cause-effect relationship matrix for dimensions in expert C.

\begin{tabular}{cccccccccc}
\hline & $D_{1}$ & $D_{2}$ & $D_{3}$ & $d$ & $r$ & $d+r$ & Rank & $d-r$ & Rank \\
\hline$D_{1}$ & 1.7 & 1.8 & 2.25 & 5.75 & 5.75 & 11.5 & 2 & 0 & 0 \\
$D_{2}$ & 1.8 & 1.7 & 2.25 & 5.75 & 5.75 & 11.5 & 2 & 0 & 0 \\
$D_{3}$ & 2.25 & 2.25 & 2.375 & 6.875 & 6.875 & 13.75 & 1 & 0 & 0 \\
\hline
\end{tabular}

Threshold value: 2.04 .

Step 1) Normalize ratings.

Step 2) Weight normalized ratings: (Table 16).

Step 3) Evaluate “*” solutions and “-” solutions: (Table 17).

Positive ideal: $\left(0.0386^{*}, 0.0528^{*}, 0.128^{*}\right)$

Negative ideal: $\left(0.0082^{-}, 0.0057^{-}, 0.0065^{-}\right)$

Step 4) Obtain separation measures:

$$
\begin{gathered}
S_{i}^{*}=\sqrt{\sum_{j=1}^{n}\left(v_{i j}-v_{j}^{*}\right)^{2}} \text {, we got } S_{i}^{*}=(0,0.045,0.13), \quad \text { rank }=C \succ B \succ A . \\
S_{i}^{-}=\sqrt{\sum_{j=1}^{n}\left(v_{i j}-v_{j}^{-}\right)^{2}} \text {, we got } S_{i}^{-}=(0.53,0.1,0), \text { rank }=A \succ B \succ C .
\end{gathered}
$$

Step 5) Find similarities to positive ideal solution: (Table 18). 
Table 16. Weighted normalized ratings.

\begin{tabular}{cccc}
\hline Weight & 0.2 & 0.3 & 0.5 \\
\hline Criteria/Dimensions & $D_{1}$ & $D_{2}$ & $D_{3}$ \\
Expert $A$ & $0.193\left(C_{12}\right)$ & $0.176\left(C_{21}\right)$ & $0.256\left(C_{35}\right)$ \\
Expert B & $0.076\left(C_{11}\right)$ & $0.048\left(C_{22}\right)$ & $0.222\left(C_{35}\right)$ \\
Expert $C$ & $0.041\left(C_{11}\right)$ & $0.019\left(C_{21}\right)$ & $0.013\left(C_{33}\right)$ \\
\hline
\end{tabular}

Table 17. Evaluation of “»” solutions and “-” solutions.

\begin{tabular}{cccc}
\hline Criteria/Dimensions & $D_{1}$ & $D_{2}$ & $D_{3}$ \\
\hline Expert $A$ & $0.0386^{*}$ & $0.0528^{*}$ & $0.128^{*}$ \\
Expert B & 0.0152 & 0.0144 & 0.111 \\
Expert $C$ & $0.0082^{-}$ & $0.0057^{-}$ & $0.0065^{-}$ \\
\hline
\end{tabular}

Table 18. List of candidate dimensions and criteria.

\begin{tabular}{|c|c|c|c|c|}
\hline \multirow[b]{2}{*}{ Expert } & \multirow[b]{2}{*}{$\begin{array}{c}\text { Candidate } \\
\text { (dimensions) }\end{array}$} & \multicolumn{3}{|c|}{ Candidate (Criteria) } \\
\hline & & $\begin{array}{c}D_{1} \\
\text { Economic and } \\
\text { financial barriers }\end{array}$ & $\begin{array}{c}\qquad D_{2} \\
\text { Political and regulatory } \\
\text { barriers }\end{array}$ & $\begin{array}{c}\mathrm{D}_{3} \\
\text { Geographical and ecosystem } \\
\text { barriers }\end{array}$ \\
\hline$A$ & $D_{3}$ & $\begin{array}{l}\qquad C_{12} \\
\text { Long investment } \\
\text { return period }\end{array}$ & $\begin{array}{c}C_{21} \\
\text { Lack of waste disposal } \\
\text { regulations }\end{array}$ & $\begin{array}{l}C_{35} \\
\text { Different geographical and } \\
\text { topographical influences have } \\
\text { a different exposure time }\end{array}$ \\
\hline$B$ & $D_{3}$ & $\begin{array}{c}C_{11} \\
\text { High initial capital } \\
\text { cost }\end{array}$ & $\begin{array}{c}C_{22} \\
\text { Lack of waste recycling } \\
\text { system }\end{array}$ & $\begin{array}{l}C_{35} \\
\text { Different geographical and } \\
\text { topographical influences have } \\
\text { a different exposure time }\end{array}$ \\
\hline$C$ & 0 & $\begin{array}{c}C_{11} \\
\text { High initial capital } \\
\text { cost }\end{array}$ & $\begin{array}{c}C_{21} \\
\text { Lack of waste disposal } \\
\text { regulations }\end{array}$ & $\begin{array}{c}C_{33} \\
\text { Cause land pollution }\end{array}$ \\
\hline
\end{tabular}

$$
C_{i}^{*}=\frac{S_{i}^{-}}{S_{i}^{*}+S_{i}^{-}} \text {, we got } C_{i}^{-}=(1,0.68,0), \quad \text { rank }=A \succ B \succ C .
$$

Step 6) Rank preference order:

rank $=A \succ B \succ C$, therefore,

rank $=(0.0386,0.0528,0.128) \succ(0.0152,0.0144,0.111)$

$\succ(0.0082,0.0057,0.0065)$.

\subsection{Results and Discussion}

\subsubsection{Results}

The outcome of ranking is as follows: $C_{12}, C_{21}, C_{35}$ (expert A); $C_{11}, C_{22}, C_{35}$ (expert B); and $C_{11}, C_{21}, C_{33}$ (expert C). These results are presented in Table 18. In terms of the first dimension (i.e., economic and financial barriers) $C_{11} \succ C_{12}$; in the second dimension (i.e., political and regulatory barriers), $C_{21} \succ C_{22}$; and in the 
third dimension (i.e., geographical and ecosystem barriers), $C_{35} \succ C_{33}$. The highest-ranked criteria are $C_{35}$. TOPSIS ranked the experts as follows: $A \succ B \succ C$. Therefore, the choice of expert A represents the greatest barriers to the development of solar energy in Taiwan. The dimension with the greatest weight is the geography and ecosystem barriers of Taiwan. Within this dimension, the different exposure times required by solar panels installed in different locations due to different geographic and topographical influences make the application of solar energy difficult.

\subsubsection{Discussion}

This finding is supported by a robust body of literature: for example, the performance of solar panels is greatly affected by the intensity of sunlight, solar energy is usually intermittent, with limited daytime hours. India has become one of the best receiving countries for solar energy due to its advantageous position in the solar belt [13]. Pakistan is located in the solar belt and receives a lot of sunlight through the year [17]. China has the advantage of a large area, and it is also in the solar belt, due to scattered settlement patterns, the rural areas and underserved communities are characterizing [20]. In Vietnam's solar photovoltaic land lease payment exemption, it depends on the location [21]. The above is consistent with the finding of this research $C_{35}$.

According to the comments of [8] [11] [13], various materials of solar panels and electromagnetics is toxic to the environment and have a significant impact on the ecological environment, which ecological issues are consistent with the finding $D_{3}$ of this research.

\section{Conclusion}

Our research results indicate that Taiwan's natural environment represents the greatest barrier to the development of solar energy, as its geographical and topographical factors have a negative effect in terms of the duration and intensity of sunshine. These findings serve as a reference for policymakers and industry investors. There remain opportunities to develop solar energy; however, the major factor of limited locations for installation must be considered in policy development. All three major system types, namely land, rooftop, and water, have already been maximized. Innovative approaches will be required to overcome the natural limitations of Taiwan to support the ongoing development of solar energy.

\subsection{Academic Implication}

The results of this study can be used as a reference for the Taiwan Energy Development Center and the Urban Development Bureau, as well as for students studying renewable energy.

\subsection{Limitations of the Paper}

The limits of this research are based on the actual environment of Taiwan, other areas with similar environments to Taiwan. Welcome to refer to and provide 
valuable opinions.

\subsection{Future Studies and Recommendations}

The ultimate goal of this paper is to make recommendations to policymakers with limited land resources in Taiwan. Meanwhile, also we can learn from the idea of the Dutch innovative solar bike path [31] [32], create new thinking into the development of solar power to preciously and utility to optimize Taiwan's land effectiveness, to relieve the dilemma between Taiwan's land and power developed, and make Taiwan's economy take a big step toward a milestone. And provide other geographic and topographical environments in the world that are in the same situation as Taiwan to reference. This research method uses DEMATEL to integrate TOPSIS to explore the obstacles to the solar energy development in Taiwan, we will continue to use ingenuity and find innovative ideas and combine the optimal algorithm research method to continue retrieving study.

\section{Conflicts of Interest}

The author declares no conflicts of interest regarding the publication of this paper.

\section{References}

[1] Tzeng, G.H., Chiang, C.H. and Li, C.W. (2007) Evaluating Intertwined Effects in E-Learning Programs: A Novel Hybrid MCDM Model Based on Factor Analysis and DEMATEL. Expert Systems with Applications, 32, 1028-1044. https://doi.org/10.1016/j.eswa.2006.02.004

[2] Hwang, C.L. and Yoon, K. (1981) Methods for Multiple Attribute Decision Making. In: Multiple Attribute Decision Making, Springer, Berlin, Heidelberg, 58-191. https://doi.org/10.1007/978-3-642-48318-9 3

[3] Kung, C.C. and McCarl, B.A. (2020) The Potential Role of Renewable Electricity Generation in Taiwan. Energy Policy, 138, 111227.

https://doi.org/10.1016/j.enpol.2019.111227

[4] Liou, H.M. (2010) Policies and Legislation Driving Taiwan's Development of Renewable Energy. Renewable and Sustainable Energy Reviews, 14, 1763-1781. https://doi.org/10.1016/j.rser.2010.02.013

[5] Fthenakis, V.M. (2000) End-of-Life Management and Recycling of PV Modules. Energy Policy, 28, 1051-1058. https://doi.org/10.1016/S0301-4215(00)00091-4

[6] Tsoutsos, T., Frantzeskaki, N. and Gekas, V. (2005) Environmental Impacts from the Solar Energy Technologies. Energy Policy, 33, 289-296. https://doi.org/10.1016/S0301-4215(03)00241-6

[7] Sumner, S.A. and Layde, P.M. (2009) Expansion of Renewable Energy Industries and Implications for Occupational Health. JAMA, 302, 787-789.

https://doi.org/10.1001/jama.2009.1214

[8] Kannan, N. and Vakeesan, D. (2016) Solar Energy for Future World: A Review. Renewable and Sustainable Energy Reviews, 62, 1092-1105. https://doi.org/10.1016/j.rser.2016.05.022

[9] D’Adamo, I., Miliacca, M. and Rosa, P. (2017) Economic Feasibility for Recycling of Waste Crystalline Silicon Photovoltaic Modules. International Journal of Photoenergy, 2017, Article ID: 4184676. https://doi.org/10.1155/2017/4184676 
[10] Kabir, E., Kumar, P., Kumar, S., Adelodun, A.A. and Kim, K.H. (2018) Solar Energy: Potential and Future Prospects. Renewable and Sustainable Energy Reviews, 82, 894-900. https://doi.org/10.1016/j.rser.2017.09.094

[11] Majewski, P., Al-shammari, W., Dudley, M., Jit, J., Lee, S.H., Myoung-Kug, K. and Sung-Jim, K. (2021) Recycling of Solar PV Panels-Product Stewardship and Regulatory Approaches. Energy Policy, 149, 112062. https://doi.org/10.1016/j.enpol.2020.112062

[12] Ansari, M.F., Kharb, R.K., Luthra, S., Shimmi, S.L. and Chatterji, S. (2013). Analysis of Barriers to Implement Solar Power Installations in India Using Interpretive Structural Modeling Technique. Renewable and Sustainable Energy Reviews, 27, 163-174. https://doi.org/10.1016/j.rser.2013.07.002

[13] Luthra, S., Kumar, S., Garg, D. and Haleem, A. (2015) Barriers to Renewable/Sustainable Energy Technologies Adoption: Indian Perspective. Renewable and Sustainable Energy Reviews, 41, 762-776. https://doi.org/10.1016/j.rser.2014.08.077

[14] Wyllie, J.O., Essah, E.A. and Ofetotse, E.L. (2018) Barriers of Solar Energy Uptake and the Potential for Mitigation Solutions in Barbados. Renewable and Sustainable Energy Reviews, 91, 935-949. https://doi.org/10.1016/j.rser.2018.04.100

[15] Ghimire, L.P. and Kim, Y. (2018) An Analysis on Barriers to Renewable Energy Development in the Context of Nepal Using AHP. Renewable Energy, 129, 446-456. https://doi.org/10.1016/j.renene.2018.06.011

[16] Shah, S.A.A., Solangi, Y.A. and Ikram, M. (2019) Analysis of Barriers to the Adop tion of Cleaner Energy Technologies in Pakistan Using Modified Delphi and Fuzzy Analytical Hierarchy Process. Journal of Cleaner Production, 235, 1037-1050. https://doi.org/10.1016/j.jclepro.2019.07.020

[17] Irfan, M., Zhao, Z.Y., Ahmad, M. and Mukeshimana, M.C. (2019) Solar Energy Development in Pakistan: Barriers and Policy Recommendations. Sustainability, 11, 1206. https://doi.org/10.3390/su11041206

[18] Solangi, Y.A., Longsheng, C. and Shah, S.A.A. (2021) Assessing and Overcoming the Renewable Energy Barriersfor Sustainable Development in Pakistan: An Integrated AHP and Fuzzy TOPSIS Approach. Renewable Energy, 173, 209-222. https://doi.org/10.1016/j.renene.2021.03.141

[19] Zhao, Z.Y., Chen, Y.L. and Li, H. (2019) What Affects the Development of Renewable Energy Power Generation Projects in China: ISM Analysis. Renewable Energy, 131, 506-517. https://doi.org/10.1016/j.renene.2018.07.063

[20] Asante, D., He, Z., Adjei, N.O. and Asante, B. (2020) Exploring the Barriers to Renewable Energy Adoption Utilizing MULTIMOORA-EDAS Method. Energy Policy, 142, Article ID: 111479. https://doi.org/10.1016/j.enpol.2020.111479

[21] Do, T.N., Burke, P.J., Baldwin, K.G. and Nguyen, C.T. (2020) Underlying Drivers and Barriers for Solar Photovoltaics Diffusion: The Case of Vietnam. Energy Policy, 144, Article ID: 111561. https://doi.org/10.1016/j.enpol.2020.111561

[22] Map of Taiwan Showing Tropic of Cancer $\left(23.5^{\circ} \mathrm{N}\right)$ Passing through Chiayi County and Hualien County.

http://library.taiwanschoolnet.org/gsh2007/gsh4867/chinese/a11.htm

[23] Taiwan Ministry of Economic Affairs (TMOEA) (2021). https://www.moeaboe.gov.tw/ECW/populace/home/Home.aspx

[24] Solar System Types in Taiwan. https://blog.sunnyfounder.com/2020/12/24

[25] Mostafaeipour, A., Alvandimanesh, M., Najafi, F. and Issakhov, A. (2021) Identifying Challenges and Barriers for Development of Solar Energy by Using Fuzzy Best- 
Worst Method: A Case Study. Energy, Article ID: 120355. https://doi.org/10.1016/j.energy.2021.120355

[26] McFarland, E.W. (2014) Solar Energy: Setting the Economic Bar from the Top-Down. Energy \& Environmental Science, 7, 846-854. https://doi.org/10.1039/C3EE43714K

[27] Raugei, M., Bargigli, S. and Ulgiati, S. (2007) Life Cycle Assessment and Energy PayBack Time of Advanced Photovoltaic Modules: CdTe and CIS Compared to Poly-Si. Energy, 32, 1310-1318. https://doi.org/10.1016/j.energy.2006.10.003

[28] Shahsavari, A. and Akbari, M. (2018) Potential of Solar Energy in Developing Coun tries for Reducing Energy-Related Emissions. Renewable and Sustainable Energy Reviews, 90, 275-291. https://doi.org/10.1016/j.rser.2018.03.065

[29] Price-Whelan, A.M., Sipőcz, B.M., Günther, H.M., Lim, P.L., Crawford, S.M., Conseil, S., et al. (2018) The Astropy Project: Building an Open-Science Project and Status of the v2.0 Core Package. The Astronomical Journal, 156, 123.

https://doi.org/10.3847/1538-3881/aabc4f

[30] Tranfield, D., Denyer, D. and Smart, P. (2003) Towards a Methodology for Develop ing Evidence Informed Management Knowledge by Means of Systematic Review. British journal of management, 14, 207-222. https://doi.org/10.1111/1467-8551.00375

[31] Shekhar, A., Kumaravel, V.K., Klerks, S., de Wit, S., Venugopal, P., Narayan, N. and Zeman, M. (2018) Harvesting Roadway Solar Energy-Performance of the Installed Infrastructure Integrated PV Bike Path. IEEE Journal of Photovoltaics, 8, 1066-1073. https://doi.org/10.1109/JPHOTOV.2018.2820998

[32] Coutu, R.A., Newman, D., Munna, M., Tschida, J.H. and Brusaw, S. (2020) Engineering Tests to Evaluate the Feasibility of an Emerging Solar Pavement Technology for Public Roads and Highways. Technologies, 8, 9.

https://doi.org/10.3390/technologies8010009 